\title{
1. Introduction: contesting the conservative antinomies of trade theory
}

International trade matters profoundly and provokes furious controversy. The overwhelming majority of professional economists champion free trade. At the same time a vociferous minority sees free trade as unfair trade, insisting the apparent freedoms are illusory and that trade relations are exploitative.

On both sides there are powerful scholarly literatures. The theory of comparative advantage, in particular, has occupied a crucial place in the liberal canon for nearly 200 years and remains the cornerstone of mainstream international economics (Ricardo 1951; Krugman and Obstfeld 2003). It is the starting point for the World Trade Organization (WTO 2014) and the basis on which Bhagwati (2002) can dismiss opponents as impassioned but irrational. For orthodoxy, trade extends the efficiency of markets across borders. For Marshall, one of the founders of mainstream neo-classical economics, trade may even provide the very 'causes which determine the economic progress of nations' (2009: 225).

Some of the critical ideas have fallen out of fashion since the 1970s but many of the central insights are still defended, particularly in relation to persistent problems of development in the poorest parts of the world (Bracking and Harrison 2003; Bush 2004; Bieler and Morton 2014). There are powerful arguments that it is state strategies, rather than free markets, that enable some countries to escape poverty and underdevelopment (Chang 2002). Again, several writers go further and find in trade the fundamental causes of international wealth and poverty (Emmanual 1972; Wallerstein 1974).

There is a lot at stake. Trade volumes are huge and have increased steeply in recent decades, both in absolute terms and relative to national incomes. Trade is growing in importance.

A visit to any standard textbook will confirm a simple dualism dominates the debates. Trade policy is presented as if it involved a straightforward choice between openness and closure (for example, Sloman and Norris 1999). This is not very helpful. More careful study 
soon reveals that even its supporters acknowledge that conventional, pro-free trade theory relies on invalid assumptions. The theoretical premises are 'relaxed' and all sorts of minor and occasional modifications and qualifications are admitted but any such amendments are seldom allowed to interfere with the confident conclusions that free trade brings mutual benefits. A variety of more or less radical critics can then have fun with the faulty assumptions of the mainstream. They can highlight examples where trade brings systematic disadvantages. Unfortunately, the criticisms too easily flip into an equally unsupported generalization that trade is injurious and iniquitous. So debates about international trade too often and too easily regress to a simplistic antagonism for or against free trade, or between market and state-led strategies.

Such binaries are misleading and conservative. If the object is depicting how the global economy actually works, rather than constructing a phantom economics for a world elsewhere, neither free trade nor protection are appropriate starting points. Free trade theory plays an important rhetorical role in encouraging a particular kind of opening, a reduction of tariffs and other barriers. But the gap between theory and a genuinely laissez-faire world never really closes. As Friedman (1962) acknowledges, there is an inherent tension between the freedom within markets and the freedom of others to restrict them. In the broadest sense, trade means an 'exchange of commodities for money or other commodities' (OED 1982). This takes place within as well as between countries. Most liberals admit that some 'market imperfections' within countries can justify state regulation. There are goods whose production is banned or whose trade is legitimately restricted. Protection of both consumers and corporate intellectual property is routinely accepted. Impeccably liberal writers from Mill (1994) to Walras (see Kolm 1968) have advocated land nationalization because of the inevitable lack of a free market. As Polanyi (2001) argues, state support is always needed to underwrite markets not just in land but also in those other 'fictitious commodities': labour and money. Free trade's most famous proponents, Smith and Ricardo, allowed many exceptions. Even the most dogmatic of contemporary free-traders would presumably baulk at the free exchange of drugs, people and nuclear weaponry (Reich 1991). So while abstract liberal theory takes support for free trade as axiomatic, this can prove fragile.

Trade openness in practice has almost always been a question of degree. All states maintain some restrictions. The phenomenal rise in trade of recent years can also be read as a process of 'managed openness' in which states continue to restrict trade in some dimensions but also to actively promote it in others (Weiss 1999, 2005). A huge quantity of trade also remains, and perhaps becomes increasingly, unfree in the sense 
that it is conducted within firms. Estimates for the level of this intra-firm trade vary but figures of about a third of the total are commonly cited (Held et al. 1999; Dicken 2003; Cohn 2005). This involves a transfer of goods from one place to another but with the same firm at both ends there is no market and the price mechanism operates at most indirectly. Goods cross national boundaries and appear in the trade statistics but this is not trade at all in the sense cited earlier, with no exchange of commodities for money or other commodities. Many apparently marketbased relations are themselves more organized than free; also entailing significant doses of power and control. As Gereffi and his co-authors (2005) argue, the bureaucratic forms of organization within firms and pure market mechanisms really represent only two ends of a spectrum. The relations between clothing multinationals and their subcontractors are particularly well known. European supermarkets can actively control the production process deep inside African countries from which they import. Free trade was never the norm; nor is it yet (Krasner 1976).

The situation is even more straightforward on the other side of the fence. If free trade has hardly been the norm, nor has autarchy. At least since the collapse of the Tokugawa shogunate in Japan, states have not chosen isolation. The closest approximations to closure have been imposed by powerful adversaries rather than adopted as strategy. States at most employ selective protection to encourage particular industries. Rather than a simple-minded protectionism what we see instead are more usually policies of state-led development. Even the early mercantilists almost always argued for something rather qualified. Writers like Mun and Child advocated a strategic use of trade restrictions and such orientations become even clearer in later authors like Hamilton and List. Similarly, important post-World War II theorists like Prebisch and Singer proposed particular restrictions or reforms to the international trade regime rather than blanket opposition. There are occasional exceptions. In the inter-war period the Romanian nationalist Manoïlescu argued for closure (Emmanuel 1972; Brolin 2006). Emmanuel (1972) does at one point advocate autarchy, although he sees little chance of its implementation. Something similar is perhaps implicit in some of the arguments of Frank and Amin but a blanket opposition to trade is rare in theory and even rarer in practice.

There are also some striking similarities between the apparently opposite perspectives. Both traditions can be seen as descendants of the weakest point in Smith's analysis. Like both lines of his descendants, Smith's objective is precisely the 'wealth of nations'. This may seem an obvious and eminently reasonable purpose but that very obviousness is telling and it is worth reflecting on why it might be a problem. The focus 
on national wealth can overlook other sources or owners of wealth. Smith also tends to privilege exchange relations and market efficiency over broader economic and social questions and much of this is repeated in both sides of the subsequent trade literature.

There is, of course, an element of caricature in presenting 200 years of trade theory as a simple dualism. There are honourable exceptions. Among mainstream economists Rodrik is perhaps the most consistent in pointing out that trade need not bring the much-vaunted benefits (for example, Rodrik 2001, 2003; Rodriguez and Rodrik 2000). In later life, Samuelson (2004) similarly raised deep questions for free trade enthusiasts, as had Keynes (1973) before him. Among the critics, several dismantle the orthodoxy, without, as far as I am aware, attempting to erect the nationalist or anti-trade alternatives that will be criticized here (for example, Shaikh 1979, 1980, 2007; Deraniyagala and Fine 2001; Deraniyagala 2005). This book is indebted to the work of these and other scholars. However, they remain relatively isolated voices. The starting points of the purportedly antagonistic perspectives are usually remarkably similar. Both tend to obscure the conditions that produce trade and which make it good or bad for particular countries and for particular groups within them.

This conservative dualism of trade theory can perhaps be understood as an example of what Bourdieu (1977: 164-71) describes as doxy and doxa. The idea is that the orthodoxy (in this case liberal trade theory) and the heterodoxy (in this case mercantilist and dependency theories) between them constitute a terrain of debate or doxy. The sound and fury of this debate draws attention to these perspectives and effectively conceals the doxa. This is the universe of the unexplored, a universe that potentially includes more radical critiques which quite literally remain out of the question. For example, rival trade theories push out of sight longstanding Marxist emphases on production but also questions of trade's potential gender and ecological implications. Skocpol (1977: 1089) similarly describes a "mirror image" trap that plagues any attempt to create a new paradigm through direct, polemical opposition to an old one ... For what seems like a direct opposite may rest on similar assumptions, or may lead ... around full circle to the thing originally opposed'. Apparent antagonisms can actually conceal shared convictions, which remain unchallenged (see also Lukes 1974; MacLean 2000).

This book's title recalls the long-time slogan of the 'International Socialists', who during the Cold War supported 'Neither Washington nor Moscow but International Socialism'. The point was to argue that Western capitalism and what they designated 'state capitalism' in the Communist countries were different versions of the same thing. Whatever 
the theoretical merits of stressing either the similarities or differences between the two sets of political economies, politically, the slogan served a useful purpose of orienting the left away from supporting either of the superpowers and towards Marx's (1974) different interpretation of socialism as working class self-emancipation. The point was to avoid arguing on a terrain of others' choosing, arguing about which superpower was preferable, rather than articulating a positive agenda. The title here suggests a similar wariness about accepting debates around trade, which limit the remit to (more or less equitable) exchange relations and frame political economy in terms of a choice between states and markets.

I am aware of an apparent irony here, that a book about trade appears to be selling a narrative which says that the importance of trade is often overstated. What I am actually arguing is that trade needs to be put in proper perspective, understood in its broader social, economic and historical context. If this book makes only limited progress towards this immense task, there are useful things that can be said and done. Of course, trade is hugely important and the critical comments are not intended to dismiss some very important arguments. Trade theories should be taken seriously but investigated critically. They should not, as too often, be imagined to capture abstract, universal truths but should be recognized as partial in two senses of the word. Trade theories are partial in articulating particular interests, but also partial in that they only capture one facet of what should properly be understood as complex social configurations. With that proviso, it becomes possible to think more critically about some of the claims being made by the different theories, to control for what they are not investigating and to question them more carefully than has often been the case.

The rest of the book is organized as follows. Chapter 2 puts trade into historical perspective, highlighting how trade relations are inextricably connected to relations of power and wealth between and within countries, are ancient but ever-changing. Findlay and O'Rourke (2007: xviii), on whose book this chapter draws extensively, write of mainstream trade theory:

If time is brought into the theory at all, and usually it isn't, this typically takes the form of allowing countries to gradually accumulate capital, breed new workers, or become better educated as a result of the voluntary decisions of rational, free individuals. The summit of unpleasantness attainable in such models is the use of tariffs, quotas and other trade policy instruments that will benefit some individuals or groups (and possibly nations) but lower the utility of other domestic or foreign residents. 
If only life were like this ... the greatest expansions of world trade have tended to come not from the bloodless tâtonnement of some fictional Walrasian auctioneer but from the barrel of a Maxim gun, the edge of a scimitar, or the ferocity of nomadic herdsmen.

Trade has seldom been a general good or evil and usually benefits some people to the detriment of others, not necessarily in equal proportion. The history also makes clear that until quite recently, national boundaries were not clearly defined and the meaning and measures of international trade are necessarily vague. The history also helps to provide the context in which rival theories were developed. Ideas are not straightforward reflections of the social and economic condition of their authors but they cannot be understood without understanding those contexts. Smith and Ricardo were products of and spokespeople for British capitalism in its dynamic youth. Figures like Hamilton and List were avowed representatives of competing but weaker national capitalisms. Several authors in the dependency tradition might be seen in a similar light. There is not a direct personal mapping and key figures like the American Wallerstein and the Graeco-French Emmanuel attempted to speak for the anticolonial revolts rather than their own 'national' interests, but still the hopes and possibilities of a changing world conditioned what was thought wrong and what was thought possible.

Chapters 3 to 5 look in some detail at important trade theories. The first focuses on mainstream arguments, especially comparative advantage. This is territory well covered and readers familiar with the key claims and criticisms may safely skip the chapter. However, many people are exposed to one side or the other of these debates; either failing to appreciate the theoretical power of the underlying claims of the theory of comparative advantage or the assumptions on which the case for free trade is built and the problems they entail. It is discussed, in particular, how comparative advantage assumes perfect markets, and ignores time, space and the role of money. The anti-free trade perspectives are divided into two chapters, largely for ease of presentation because there is something closer to a continuum rather than a neat separation into distinct schools of thought.

Chapter 4 looks at what might be seen as the moderate opposition, which tends to couch the problems in terms of market imperfections. It considers the long tradition of mercantilism, of trade restrictions and industrial promotion, and the ideas developed in the post-World War II period of poorer-country disadvantage and deteriorating terms of trade. It also considers 'New Trade Theory', particularly articulated by Krugman, 
which argues that market imperfections can be mobilized to national advantage by the governments of large, rich countries.

Chapter 5 focuses on ostensibly more radical ideas of imperialism, dependency and unequal exchange. The criticisms mentioned above, in particular on the limits of radical nationalism and the focus on exchange relations, are extended and it is argued particularly that unequal exchange provides an inadequate explanation of systemic inequality.

Chapters 6 to 9 consider evidence from the 1960s onwards and perform a series of empirical tests. In practice, free trade and protection have been rare, almost imaginary ends of a spectrum of trade policy. This variation provides a basis for evaluating many of the claims being made.

Chapter 6 considers the relationship between trade and economic growth. It confirms there are weak, positive associations between trade openness, and trade opening, and growth. There is some evidence for this in aggregate, for rich and poor countries and for large and small ones. The chapter finds little evidence that trade surpluses are conducive to growth. Indeed, until the 2000 s, a negative balance seems to be associated with stronger growth. There is some indication, particularly in the 1970 s, that a positive balance in primary products had a negative impact, as various theories discussed in Chapter 4 anticipate, but this is not found subsequently.

Chapter 7 looks at whether countries grow faster when they trade on the basis of 'factor endowments'. That is to say it considers the Heckscher-Ohlin theorem, one of the key corollaries of neo-classical trade theory. For each decade between 1980 and 2010 the chapter reports results that confirm quite strong and highly statistically significant associations between land endowments and the propensity to export primary products, and weaker associations between labour endowments and manufactured exports. However, to the important supplementary question whether countries do better when they trade according to the prescriptions of Heckscher-Ohlin theory, the results are much less conclusive. There was some evidence in the 1980s that, if anything, countries' economies grew more quickly when they traded according to their factor endowments but little evidence of any such association in subsequent decades. Indeed, by the 2000s, the countries that defied Heckscher-Ohlin on average grew slightly faster than those that followed its prescriptions.

Chapter 8 looks at trade and inequality within countries. It focuses on the Stolper-Samuelson theorem, an extension of the Heckscher-Ohlin theorem, which maintains that there are likely to be winners and losers within countries from both protection and trade opening. The results indicate that trade had important impacts on (in)equality but that it 
worked in more complex ways than identified by conventional theories. The chapter therefore considers how other economic processes might work alongside or apart from trade and it broadens the discussion to one of inequality as a complex social and political achievement.

Chapter 9 extends the investigation of changes within countries by looking at the relationship between trade opening and labour organization. In recent decades many countries experienced both an increase in economic openness and falling levels of industrial action. The chapter reports tests showing that an anticipated negative impact of trade openness on levels of industrial action only becomes apparent in the presence of an interaction term between the level of trade openness and countries' relative wealth. This indicated that the decline in industrial action tended to be stronger in richer countries that opened less and poorer countries that opened more, contrary to more simplistic interpretations of recent change. Further tests then confirm a markedly steeper downward trend of industrial action in manufacturing than other sectors. This is compatible with the greater pressure on manufacturing workers associated with that sector's greater spatial mobility. It might potentially be explained by the numerical decline in manufacturing in many countries, although there is no strong evidence of the effect being greater in richer countries where such decline is more severe. Finally, the chapter shows a significant process of 'disembedding' of the incidences of industrial action in particular sectors, notably in manufacturing, from national contexts. However, the processes of disembedding do not appear to be directly linked to countries' relative exposure to trade.

Chapter 10 takes up the historical story from the 1970s, where it was left in Chapter 2, to the crisis of the late 2000s. It confirms what several accounts have identified as a significant role played by trade and the development of global imbalances in producing the crisis (Wade 2009; Wolf 2010; IMF 2011). However, it understands these misalignments as the products of a wider restructuring in the global economy, itself the result of contested struggles and strategies adopted in response to the crisis of the 1970s.

Chapter 11 concludes that the theoretical binaries are simply not confirmed by the evidence. The weakness of the relation between the degree of countries' openness or closure and overall economic performance is well established empirically but seems to have impinged very little on trade theory. Trade is neither a straightforward good nor a bad. An overly narrow focus on trade obscures what are in some ways more fundamental social relations. Apart from anything else, capital investment and exploitation in production are themselves the crucial determinants of tradable surpluses. The importance of trade is specific, varying over time 
and depending on who is being considered. The generality of trade theories conceals this specific importance, notably how the systematic imbalances in the global trade regime contributed to the crisis of 2007-09.

Before going further a few disclaimers are in order. The empirical chapters use mainstream data, for example of gross domestic profit (GDP) and of trade, and should be interpreted as contributions to a critique of existing narratives rather than as providing an adequate mapping. Conventional measures are often the best available indicators of important economic facts but it should be understood that such data are inherently flawed; for convenience or for ideological reasons they ignore some activities (like housework) that add to wealth and wellbeing and include others (like rent) that add nothing. Trade data routinely suggest a global deficit, as if the Martians were engaged in unfair competition. These chapters also concentrate on merchandise trade rather than the more slippery but increasing trade in 'services'. There is much else that cannot be discussed. For example, one area where there has recently been interesting work is in the analysis of commodity chains. Selwyn (2011) describes how such accounts tend to abstract from the specifics of national political economies in which the value is being added but the considerable potential for a fruitful synthesis is not developed here. In short, there are limits to what can be achieved but it is worth trying to move forward. 